supposed to have some action in disinfecting the gland, and could at least do no harm.

Ohno and Schonback have immunized animals to trypsine, and have suggested immunization by an antitryptic serum, but I do not know if this has ever been carried out on human beings. The administration of atropine might be worth a trial on account of its inhibiting action on pancreatic secretion.

It is not impossible that some of the milder cases of this condition recover without operation, since pancreatic cysts may take their origin in a limited necrosis of the gland and escape of small quantities of secretion.

The indications as regards operative treatment are, in my opinion, to expose the pancreas through the gastrocolic omentum, to incise the peritoneum over it, and to place rubber drains to the swollen area and gauze tampons aiound to wall off the peritoneum and prevent the diffusion of the escaping secretion. It appears that more harm than good may be done by incising the pancreas itself, which might divide ducts and set free more ferments. If the gallbladder was distended I should do a cholecystotomy, and if the common bile duct appeared distended $I$ would drain this. Neither of these procedures should take much time or involve much disturbance of the parts or increase the shock. The result would then depend on the extent of the original damage to the pancreas.

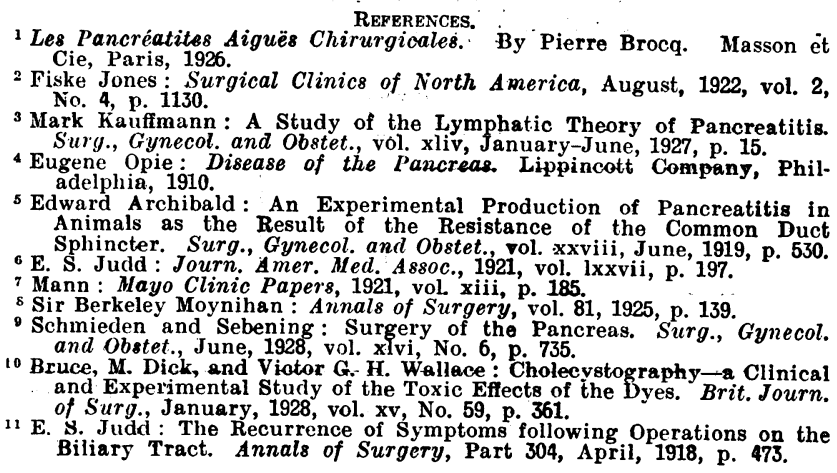

\section{THE CONTROL OF SMALL-POX*}

L. W. RAJCHMAN, M.D.,

Director of the Health Organization, League of Nations.

THE manifestations of small-pox in recent years have been characterized by (1) a very marked decrease in incidence, and (2) an almost universal decrease of the case mortality rate.

The case mortality rate has decreased partly through (a) the spread of alastrim, or a very mild type of small pox, which seems quite unaffected by the trend of the ordinary small-pox, and partly through $(b)$ a more favourable course of ordinary small-pox cases in many countries. It must be added that important outbreaks of severe smallpox have not ceased to occur, a fact of which we are reminded by the Rio de Janeiro outbreak in 1926; and that of Algeria in 1926-27.

In regard to the decrease of incidence in Europe it should be emphasized that this is not the first time it has fallen to a very low level, and also that the decrease is not universal. Though there were only 652 small-pox cases in Europe in 1927, outside the. United Kingdom, the Iberian Peninsula, and Russia, 280,000 cases were notified that year in the whole world. If we add China and parts of Africa and South America, where cases are not reported, the total number of cases must certainly have largely exceeded 300,000 . In India alone small-pox causes 50,000 deaths in an average year.

It must be borne in mind that small-pox is of a more truly epidemic character, in its year-to-year movements, than most other diseases. It attains a high incidence for some years, and falls then to a very low level. It is only

* The opening paper in a discussion in the Section of Preventive Medicine of the Annual Meeting of the British Medical Association,
Cardiff, 1928. in India that small-pox appears to be endemic at a constant level, but the size of the country accounts for this seemingly paradoxical phenomenon.

Even in the twentieth century very marked fluctuations in the incidence have been noted. A first epidemic wave occurred during the years 1901 to 1903 . In England, London and the neighbouring counties were chiefly affected in 1901 and 1902 ; Lancashire and the northern counties, in which the mild small-pox was later to become prevalent, were affected during the following two years. Small-pox caused more than 4,000 deaths in England in these four years, when the ciassical type of the disease prevailed.

In other European countries it was no better; in Belgium there were 2,938 deaths from small-pox during the three vears 1902 to 1904, with a maximum in 1903; in French towns of orer 5,000 inhabitants, 4,903 deaths from smallpox were reported in 1902 and 1903. In Italy small-pox was epidemic from 1901 to 1904, during which years it accounted for 14,951 deaths.

Further east in Europe the wave had come a few rears earlier; in Austria and Hungary its maximum occurred between 1897 and 1899, in Rumania in 1896 and 1897,' and in Russia in 1898 and 1899.

Although a high endemic level persisted in Russia, Spain, Italy, and, probably, in the Balkans, with the exception of Rumania (maximum in 1906, 1909, and 1013), there were no further serious outbreaks in England and in northern and central Europe until 1920. In Italy there were new outbreaks in 1911 and 1912, 8,164 deaths having been attributed to small-pox.

Small-pox of severe type was widespread from 1901 to 1903 also in the United States; 3,578 deaths were reported during those three years in the registration area, which then only included about one-third of the country. The incidence fell subsequently, and from 1906 to 1909 it was as low as, or lower than, it had ever been.

Small-pox was widely prevalent in Japan in 1892, 1893, and in 1897-the same years as there were extensive epidemics in eastern Europe. During the first-mentioned two years 22,261 deaths were ascribed to small-pox, and in 1897, 12,276. Its incidence subsequently fell, and in each of the years between 1900 and 1903 only from four to seven deaths from small-pox were reported, indicating a much more favourable situation than in any of the years subsequent to 1915 . There was a new epidemic in 1908, which caused 5,838 deaths. The incidence of small-pox increased again in 1917, and, although it has decreased considerably in recent years, there were still 92 deaths from small-pox in 1927.

We have to wait for the years of the war to witness a renewed increase of small-pox in southern, eastern, and central Europe. In the Cnited Kingdom, the Netherlands, France, and northern Europe there was no increase; in Germany it was moderate, 448 deaths being ascribed to small-pox in 1917, and 704 in 1919. In Austria (pre-war territory) there were, on the other hand, about 50,000 cases in 1915 and 1916.

In Italy the incidence was low during the war, and reached a minimum with only 16 deaths in 1916; but in 1919 and 1920 there were severe epidemics causing 27,417 deaths. It is interesting to note that this epidemic occurred almost exclusively in southern Italy, which was the case also with the outbreak of 1901 to 1904 . The provinces particularly visited on both occasions were Apulia with Basilicata, Campania, and Sicily.

The crest of this wave of small-pox, which affected mostly eastern, southern, and central Europe, was in most countries reached in 1919 . The incidence was still very high in 1920, but after that there was a general decrease, which has continued ever since. In certain countries the fall has been quite exceptional. Thus, in Rumania, where there were 20,523 cases in 1919 , anly 2 cases were reported in 1927 . In Italy there were 34,363 cases in 1919 , and only 59 in 1927 . The number of cases reported in the Ukraine decreased from 34,730 in 1920 to 189 in 1927.

In 1927 fifteen European countries were altogether free from small-pox, while seven reported less than five cases each; in only eight countries were more than five cases reported. Exceptions to this general decrease have been extremely few. Besides England and Wales, where a mild form of small-pox began to spread in 1922, and Switzerland, where a similar mild type of "small-pox was prevalent from 
1821 to 1926 but has now entirely disappeared, only the returns for France show no decrease.

In France the number of small-pox cases fluctuated during the last nine years between a minimum of 172 in 1922 and a maximum of 572 in 1919, with 554 in 1926 . It may be added that, in contrast to England and Switzerland, the severe type is prevalent here. The incidence of smallpox in France decreased markedly, however, during the early months of 1928 . For Portugal returns are not available until the second half of 1927 , when 1,169 cases were reported, with 140 deaths. This, however, is considerably less than in the years immediately after the war; in 1919 small-pox caused 8,864 deaths.

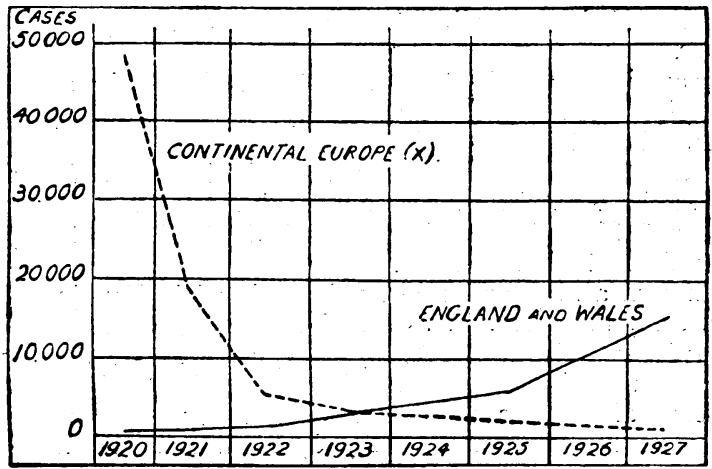

Fia. 1. - Small-pox cases reported in Europe, 1920-27. $(x)$ Without Greece, Portugal, Spain, Switzerland, and U.S.S.R.

The numbers of small-pox cases reported in European countries between 1919 and 1927 are shown in the accompanying graph (see Fig. 1). It is noteworthy that the cases, if exception be made of the epidemic of mild smallpox in northern England and that of classical type in Algeria, have occurred entirely sporadically. An investigation of these cases, carried out at the request of the Health Organization of the League of Nations by the sanitary administrations of the various countries, has proved that, with the exception of France, where at least a part of the infection seems to be traced back to Algeria, no connexion between the various cases has generally been apparent. This is particularly noteworthy in regard to the few cases that have occurred in central Europe and the Balkans.

The case mortality of small-pox varies greatly, not only from one country to another, but also from year to year.

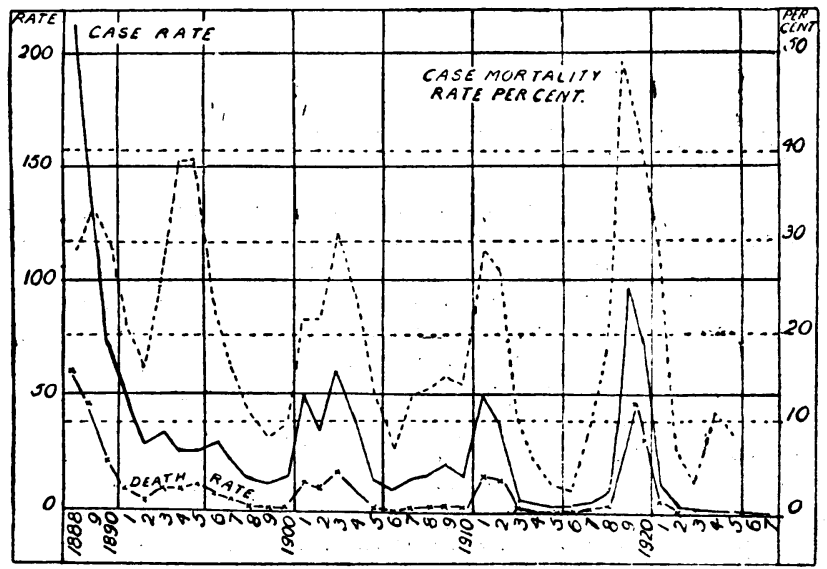

Fie. 2.-Small-pox case rate and death rate per 100,000 in

Italian statistics are very instructive in this regard. Reports, which are undoubtedly reasonably complete, are available both in regard to cases and deaths since 1888, and the number of cases and deaths have in every year been sufficiently high to establish a significant case mortality rate.

It is seen from these returns that the case mortality rate has moved in waves, generally corresponding to those described by the incidence, but even more regular in character. The accompanying diagram (Fig. 2) shows, for example, that the maxima of case mortality occurred in Italy in 1889, 1893 to $1894,1903,1911$ to 1912, and 1919; the movement of this rate was entirely regular during the intervening years, the minima being reached in 1892, $1899,1906,1915$ to 1916 , and 1923 . It would seem that a cyclo of seven or eight years existed in the height. of the case mortality rate.

The minima have gradually become lower, that of 1892 being 15.8 per cent.; that of $1899,7.2$ per cent.; that of $1906,6.8$ per cent.; that of 1916, 2.5 per cent.; and that of $1923,3.2$ per cent. The maxima were 33.8 per cent. in $1889,38.5$ per cent. in 1895,31 per cent. in 1903, 25.3 per cent. in 1912, 47.7 per cent. in 1919, and 41.7 per cent. in 1920 .

Two explanations of this phenomenon are possible: (1) the fluctuation in the degree of severity of classical smallpox, and (2) that classical small-pox might tend to disappear in certain periods, and be replaced by the milder forms. The second explanation is unlikely, however, so far as Italy is concerned, as the minima of the case mortality rate have mostly been reached in years when small-pox is relatively rare. There is no reason to believe that changes in vaccinal conditions could produce such periodical changes in the case mortality rate. Statistics of deaths are not, as yet, available for 1926 and. 1927; but a special report prepared by the Italian Health Service states that the type of small-pox prevailing during these two last years has not been very severe, and the fatal cases have been rare.

Japanese statistics for the years 1881 to 1927 also show marked fluctuations of the case mortality rate. These

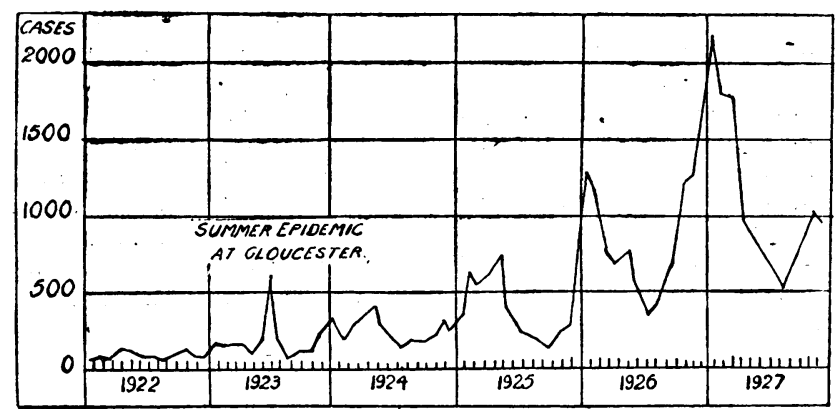

Fia. 3.-Small-pox cases reported in England and Wales, by four-weekly periods, 1922-27.

fluctuations have been less regular than those observed in Italy, but this may partly be due to the fact that the number of cases in Japan during several periods, notably from 1900 to 1906, and from 1909 to 1916; has been very low, and chance fluctuations of the rate have to be taken into account. Clearly defined maxima, however, have occurred in connexion with the epidemic outbreaks of $1886,1893,1897$, and 1908. On the latter two occasions an increase of the case mortality rate to a maximum occurred in a year preceding the epidemic. The case mortality rate fell markedly from 1919 to 1926, but in 1927 it increased again, and it is obvious that the average rate is not lower now than it was forty or fifty years ago. It is evident that the fall of the case mortality rate which occurred after 1920 in England and Wales is not of the same nature as the fluctuations which we have just shown for Italy and Japan.

The case mortality rate was 11.4 in 1920 in England and Wales; it fell during the following year to 1.6 , and to 2.8 in 1922 , after which it decreased to 0.3 ; it has remained between 0.2 and 0.3 ever since. The figure of 2.8 for 1922 is really misleading. It is due to an outbreak of classical small-pox in the London area, comprising 78 cases with 24 deaths, giving a case mortality rate of 31 per cent. There were thus in the remainder of the country 895 cases with only three deaths, giving the case mortality rate of 0.3 as in the following years.

The mild type of small-pox is said to have made its appearance in England in 1919 . It was evidently not until a few years later that it entirely overshadowed the isolated outbreaks of classical type, and it is clear that from that moment the case mortality rate fluctuated around a level different from that of former times. (See Fig. 3.) 
The statistics for the United States Registration Area for deaths show that the fall in the case mortality rate preceded that of England. While, up to the end of the nineteenth century, the case mortality is known to have been about 20 per cent. in the States belonging at the time to the registration area, it had already fallen to between 3 and 4 per cent. during the first five years of the twentieth century. A sudden and decisive fall below 1 per cent. was recorded in 1yub, and it has remained at this level with a few sharp variations. When the case mortality rate rose above 1 per cent. in 1910,1922, 1924, 1925, and 1926, it was due to fairly isolated outbreaks of small-pox of severe type, believed to have been imported from Mexico. The outbreaks in Detroit in 1924, in Minneapolis in 1925, and in Los Angeles in 1926 were of this type, and operated much in the manner of the 1922 London outbreak in swelling the general rate for the country as a whole.

In continental Europe the case mortality rate appears to have fluctuated on the level typical for classical smallpox, with the exception of Switzerland, where the mild type of the disease between 1921 and 1925 gave a figure of 0.2 per thousand cases, similar to that for England and Wales.

In Germany the rate varied between 12 per cent. and 16 per cent. during the years 1919 to 1922 , when the disease was fairly widespread. From 1923 to 1927 only 68 cases were reported in Germany with 26 deaths, a rate of 39 per cent. For France the figures were between 28 and 29 per cent. from 1919 to 1921 , and 24.8 per cent. in 1925. Statistics of deaths for the years 1922 to 1924 have not yet been published. In Portugal the figure was 12 per cent. during the second half of 1927, although it had been considerably higher in previous years; in 1925 it was 34 per cent. in Lisbon and Oporto. In Rumania the figure stood at 28.4 per cent. during the severe epidemic of 1919 ; it decreased gradually as the incidence became lower, and was 12.4 in 1923. It has not fallen appreciably since, 5 deaths having been reported for the 46 cases notified during the last four years. In the kingdom of the Serbs, Croats, and Slovenes the figure was between 22.6 and 22.8 during the years 1920 to 1922, 19.1 in 1923, and 19.4 in 1924. No further increase has occurred, 5 deaths having been reported with the 21 cases notified in these last three years. The type of small-pox prevailing in Greece is said to have become milder than formerly; 2,101 cases with 683 deaths were reported in 1923, giving a case mortality rate of 32 per cent. In 1927 there were 22 cases, with 3 deaths, reported as small-pox, and 93 cases, without any deaths, reported as varioloid.

The figure in extra-European countries falls generally between 10 per cent. and 30 per cent. In India it was between 24 per cent. and 25 per cent. in relation to the reported cases in 1926 and 1927. In Korea it was between 23 and 24 per cent. during the same years.

Interesting fluctuations have occurred in Java, where the figure decreased from 25 per cent. in 1912 to 12.1 per cent. in 1917, rose again to 26 per cent. in 1918, and gradually decreased to 12.3 per cent. in 1923, to rise once more to 21.8 per cent. in 1924. There has since been a decrease, and it was only 2.7 per cent. in 1927-an exceptionally low figure for a tropical country.

The reported rate in Egypt has usually fluctuated between 20 and 30 per cent., and has become lower during recent years, as it was 14.2 per cent. in 1927. Statistics for various African colonies, such as the Gold Coast, Nigeria, and northern Rhodesia, show that small-pox epidemics with a fairly low case mortality rate $(2$ to 10 per cent.) are not rare. There are, however, occasionally epidemics of a much more severe type having a case mortality rate of 30 per cent. or more. For the southern part of Africa the rate is certainly influenced by Kafir-pox, which is distinctly of the benign type.

The general impression gained as to the case mortality rate actually obtaining in the various parts of the world is that two entirely distinct types prevail: (1) the classical type, the rate of which is fluctuating in long waves, geneially between 10 per cent. and 30 per cent., and (2) the mild type, with figures between 0.1 per cent. and 0.3 per cent. The periods of minima presented by the classical type do not appear, in any way, to be intermediate between that and the mild type.

Small-pox deaths have been too rare in recent years in most European countries to establish reliable death rates by age. Italian statistics for 1918 to 1921 show very marked excess in the female death rate at ages between 20 and 44 (see Fig. 4); the low incidence among males at this age may be explained by vaccinations during military service. At ages under 15 the difference in rate between boys and girls was very slight; at ages over 55 there was

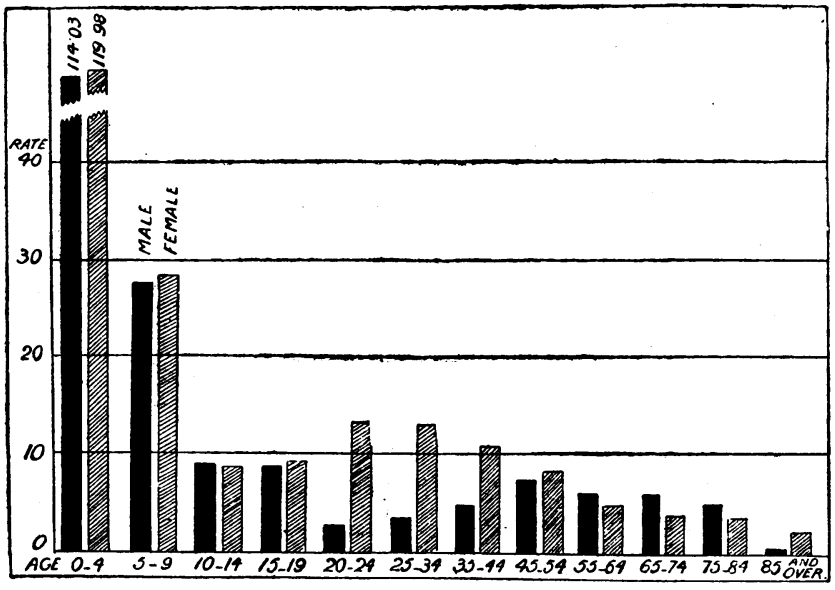

Fig. 4.-Small-pox death rate by sex per 100,000 population in

an excess of male mortality. These figures correspond to the rates for 1901 to 1905 , except that the excess of female mortality as shown in 1918 to 1921 was not.noticeable.

The age distribution of small-pox deaths is greatly influenced by the vaccinal condition obtaining in a given country, and it is difficult to determine whether fluctuations due to any other cause occur.

The seasonal distribution of mild small-pox does not appear to differ materially from that of the severe type. Both have usually their maximum in winter or early spring, although one or two notable recent exceptions are on record.

\section{THE SERUM CALCIUM IN EXPERIMENTAL TUBERCULOSIS.* \\ BY}

J. CLTFFORD HOYLE, M.B., B.S.

(From the Pharmacological Laboratory, Cambridge.)

Turkrculosis has long been recognized to be associated with changes in calcium metabolism. For example, a close relationship exists between arrest and calcification of lesions, and, apart from this, tuberculous tissues often contain many times the normal amount of calcium. Earlier observers held that a " demineralization" occurred during the disease, due to increased excretion of mineral elements. This has since been disproved repeatedly, and, so far as calcium is concerned, there is no sound evidence for any decreased retention during tuberculous infections, except possibly in the terminal stages.

During recent years reliable methods for estimating the serum calcium have been found, and a number of investigations in clinical tuberculosis have been published. Several workers found no changes, ${ }^{1}$ but the balance of evidence shows that in active phthisis the serum calcium is lowered, and in arrested disease is raised, on the average. $^{2}$ No attempts have been made to explain the cause of these results: whether the fall is associated solely with the tuberculous infection or is due in part to superimposed secondary infection remains doubtful. Some evidence strongly suggests that secondary and septic infections lower the serum calcium, ${ }^{3}$ and I propose to offer further proof of this. Clinical observations on phthisis

* Read in the Section of Tuberculosis of the Annual Meeting of the British Medical Association, Cardiff, 1928. 